\title{
Reading Strategies and Promotion in Canadian Schools (with particular attention to the needs of teen age boys)
}

\author{
Gerald R. Brown \\ Consultant, School Library \& Information Services \\ Honorary Ambassador, International Association of School Librarianship \\ IASL Special Interest Group - International Development \\ 3403-55 Nassau Street North \\ Winnipeg, Manitoba, Canada
}

\begin{abstract}
:
An examination of issues related to reading in free time, in classrooms and in school libraries with young people ages $12-16+$, with particular attention to teen age boys. It concentrates on implementation strategies that have been effective, and which can be used by both teachers and teacher-librarians to integrate the Reading (Literary \& Cultural Appreciation) component of SLIS into the regular curriculum activities in the classroom and across the school programs.

Opportunities will be provided for group participation, through discussion and through sharing of ideas that have been successful in local areas.
\end{abstract}

Addressing the reading needs of learners effectively will require dialogue and the collective expertise and talents of all partners in the education process, including government, educators, librarians, parents and community members.

However, among these partners, educators play a particularly important role in determining how individual learners develop as readers, writers and thinkers. It is critical that we provide classroom experiences that respond to the interests, needs and learning styles of all students and that we explore ways to engage boys and girls equally.

\section{Can't read or don't read ?}

G. Kylene Beers identifies three distinct categories of students who can read but don't:

- the dormant reader: "I'm too busy right now!"

- the uncommitted reader: "I might be a reader, someday."

- the unmotivated reader: "I'm never gonna like it!"

Beer concludes that there is no single 'template' for the aliterate student; rather, there are individuals who have differing views about themselves and reading. By understanding these views, we can gain greater insight into why some students choose not to read.

Beer, 1996, pp. 31-33 
Although gender is a significant factor, it is not the only factor at play in determining performance in reading, writing and thinking. In fact the differences among boys and among girls are greater than the differences between boys and girls. To address these needs, the Ontario (Canada) Ministry of Education produced a landmark document entitled

“Me Read? No Way! A Practical Guide to Improving Boys' Literacy Skills.”

It is a 58 page summary of the research related to helping boys become better readers. It is available on line. Every teacher and teacher-librarian should have it as required reading. The ideas are outstanding; the techniques superb.

Today, we are invited to address the various kinds of reading promotion that are done in Canadian schools. The time is far too short to provide the details of many of these fine programs. However, some aspects will be provided and directions given to other sources. The bibliography will set out fine tools that are available, many of them on-line.

It is quite apparent that there are three (3) things necessary for a successful reading program:

.1 a teacher-librarian who models a love of reading, who reads voraciously and who communicates this excitement to both students and teachers

.2 a well-stocked library selected by a person who is in tune with student interests and needs, and who knows how to involve both teachers and students in building the collection for the both the library and for the classrooms

.3 students, who have the time, or are encouraged to take the time, to explore the adventures of reading, and then invited to share their personal adventures with others through their responses to the literature.

We need also to remember that the collection must contain all kinds of material - both print and electronic - in order to respond to the learners. Fiction will be attractive to some; nonfiction will be the choice for others. Access to the electronic media both in school and outside provides alternative sources for literary and cultural experiences at all ages.

\section{Have the Right Stuff}

Well-stocked collections in the library and in the classroom are the basis for developing a reading habit. Does your school provide:

- Both fiction and non-fiction

- Non-print resources, such as CDs

- Texts representing a wide range of formats and genres

- Popular as well as 'traditional' materials

- Lots of easy-to-read to build fluency and provide enjoyment 
In building your school collection, did you

- Invite the teachers to read and review for the selection process

- Engage the students in selecting materials for the classroom collection from the library collection, or from the bookstore

New information technologies - in particular the Internet - presents us not only with new forms of text, but also with opportunities to custom-tailor literacy activities to the interests, learning styles, and motivations of boys. Information technology offers an important opportunity to fully engage boys in reading, writing and visual literacy.

Reading A-Z .Com is an outstanding on-line resource on teaching materials, both fiction and non-fiction, for use with elementary and middle school students. It has a large collection of quality titles, supported with lesson guides, questions, and templates.

http://www.readinga-z.com

\section{Help Make Reading a Habit}

The teachers and teacher-librarian must become collaborators in finding time for reading in the classroom, in all subjects, and in the library.

2.1 Reading aloud with expression, so students can hear how a capable and fluent readers sounds. The basis for all language is the sound that it creates, its rhythm, cadences, and the way words work together. Use your voice and body to bring the words and story alive.

Use this time also to explicitly show and discuss models of good writing in detail, pointing out elements such as sentence structure, paragraphing, and choice of words, so that students become aware of the choices that the writer has made.

2.2 Book talks can fire students about a wide variety of books. The structure of the talks, the content of the materials, the enthusiasm of the story teller, and the responses of the students will be good sales techniques

2.3 Book discussions, and book clubs can draw students to share the things they have learned or found interesting in their choices

2.4 Search the Web to find tests that will capture the attention of some students for a particular kind of writing or information

2.5 Sustained Silent Reading - a time for people to enjoy quiet and privacy in what they read. Plan personal reading time for students, in regularly scheduled blocks of time every day ... either in the library or in the classroom. Setting reading targets can be helpful too.

2.6 Modelling a reading culture by all the staff is imperative. The students see what you do and follow it, more quickly that what you tell them to do. 
2.7 Helping students select books appropriate to their ability can be a bridge to finding the right starting point. As they have confidence in your guidance, and your credibility soars, you will enjoy the interaction as they come back to tell you about the last title. excitement

2.7 Writing in response to literature - nurture the creative aspect of a student's

* Have the boys nominate a prominent player for a fictional 'dream team' by having them read about their favorite sport figures and make a case for why those athletes should be on the team.

* Have the students create a "menu' of books for their peers to form a book banquet

* Encourage the students to keep a "Response Journal" as a place for students to write their reactions, questions and thoughts about literature. Writing is more than a medium of communication; it is also a means of articulating and clarifying one's own ideas, and sometimes creating new ideas in the process. The content of students' literature response journals can help the teacher and teacher library asses the reading abilities and behaviours of the student.

2.8 Acting and speaking in response to literature - provide a venue for drama, improvisation, the spoken word.

"Well-designed drama is more than an opportunity for boys to stretch their limbs. Good drama activities invite students to step into the role and combine what they know (from their own lives in the 'real' world) with the new or fictional framework offered by the drama. For students who are uncomfortable talking about their own feelings, drama offers rich opportunities to be someone else or somewhere else, and to deflect the expression of feelings into a fictitious form ... if feelings can be deflected through role-playing, unexpected fluency may result." Pirie, 2002, p. 47

\section{Reading with a Purpose / Teaching with a purpose}

It is imperative to help students learn that there are different kinds of reading and writing according to the kind of material, the kind of project, and the outcomes expected.

Teacher-librarians can work closely with the classroom teachers in designing activities that will help students develop comprehension skills in both fiction and non-fiction areas. We do this best by /when:

3.1 monitoring our own understanding of a text and make adjustments in assignments according to the needs of the student. Is the book we are suggesting appropriate to the ability of the reader? Is the assignment possible considering our collection ? Can we find alternative material on the websites ? Do we need to help the teacher re-write some of the material for particular projects?

3.2 using relevant prior knowledge of the student to help them learn to predict outcomes ... works from kindergarten with the pictures books

3.3 generating questions about the text to help us think aloud about what we know or want to discover 
3.4 drawing inferences in the written material helps students learn to read a more than one level in fiction, or look for hidden meanings in non-fiction

3.5 constructing visual representations or graphic organizers of plot lines, main and supporting ideas in a text, or relationships between characters and events. This is an area of learning that needs considerable attention when one is helping students use a problem-solving model to organize their ideas. It works in literature, literacy development and research with equal validity. E.g.

- Similarities and Difference charts

- KWL charts (Ogle 1986, p.564-570)

- Network trees or Information webs

- Sequence of events

- Story Maps to develop an appreciation of setting; an understanding of a sequence of events, or the internal logic of a story

- Character analysis charts to understand the characters and their motivations is essential to an appreciation of the plot. It requires readers to justify choices and decisions, prove evidence and find supporting details, thus developing skills such as inferential thinking, sequencing, and cause and effect.

- Developing and producing a "Character Report Card" through discussion

\section{Using Games and Role Playing to Respond to Literature}

Many of our schools have professional guest Artists / Actors Groups come to work with students in the school. The teacher-librarians are often leaders in recruiting these 'human' resources.

Some groups have been from opera associations or schools of music. They have helped students explore music without lyrics to create world lists, phrases, lyrics, descriptions of feelings, word-images, letters, dramas or dialogues. At times they have created short pieces to be performed for the whole school.

In other cases Authors/Writers-in-Residence have nurtured students to explore various kinds of creative writing in response to art, music and literary tools. The results have been quite exciting. Several students have gone on to careers in journalism and drama.

Following are some examples of the way games and role playing can enhance student's understanding of stories, novels and other texts:

- Role play a character in your novel

- Role play an imaginary character you would like to add to your novel

- Create your own short drama or play to visualize the story you have just heard, or that you have read as a group

- Do an analogy drama by enacting a story from your own lives that parallels a situation in the text 
- Write a letter to one of the characters in your story, create a diary for a week for this person, or create an advertisement for a missing person from one of your stories.

- Produce a newscast based on the characters and events in your text, novel, or sound material.

Poems, Chants and Songs come alive when given rhythmical reading. Children have fun and explore the rhythm of words, their speech, and their language skills are developed. It helps students who are second language learners. The use of nursery rhymes is very popular at this stage too.

Readers' Theatre is a way to make books come alive. It does not require memorization. The performers read from the script. It does not require elaborate costumes, music or lighting. There is very little action; the effects that turn 'reading' into 'theatre' are created by the voices of the individual and group readers. It requires that the participants engage with the text as they make decisions about:

- which parts are read by individuals and which are read by groups

- which words or phrases to stress or emphasize

- what special vocal effects: pitch, volume, tone, etc to use.

Students have the opportunity to work on different parts in the production, and to learn a little bit about theatre. There are a wide variety of titles available for this exercise. One example is Aaron Shepard's RT Page: Scripts and Tips for Reader's Theater http://www.aaronshep.com/rt/

\section{Create Discussion Opportunities - Let Them Talk}

Some people like to talk about ideas in order to understand them more clearly. The need to verbalize is important in clarifying a concept or a imaginary aspect of a topic. There are a variety of activities that are being used to help in this regard for both boys and girls.

5.1 Small shared-reading groups that include the teacher, or a parent volunteer can open up ideas about what is being read. Guided open-ended questions can be very useful here too.

5.2 Groups working together with multiple copies of the same text can provide common basis of information for sharing, prediction and inference building.

5.3 Students reading in pairs, or working with a partner from the same class for a partner/buddy from another grade can often form a bridge that gives excitement to the talking process.

5.4 Using taped stories to follow the story in a book has value for the students who are slower readers, who have difficulty pronouncing words, who need to hear a quality flow of language, or who are just aurally more attuned. Volunteers can be very helpful as monitors in this project 
5.5 Re-drafting a piece of material using the computer can be very useful for two students working together. Whether they are paired at the same ability or skill level, or whether one is a guide to the other depends on the desired learning outcome.

5.6 Using electronic mail to share a response to a piece of reading can be very stimulating for some students. At the same time it helps them develop writing skills appropriate to the topic and the audience.

5.7 Participating in on-line discussion groups within the school, district, region or internationally encourages students to read and write more widely, and with more finesse as they realize their work is being read by people in another classroom or community. e.g. http://www.iearn.org/

http://www.iearn.org/globe/index.htmlStarted in 1988, iEARN is the world's largest nonprofit global network that enables teachers and young people to use the Internet and other new technologies to collaborate on projects that both enhance learning and make a difference in the world.

\subsection{Literature Circles}

Literature circles are small, temporary discussion groups who have chosen to read the same story, poem, article or book. Some people think of them as Book Clubs or Discussion Groups.

The group members determine what they will read, at what stages the reading will be interrupted for discussion, and what topics and questions will be discussed.

Students must be taught the skills and strategies of the process before they can be expected to participate effectively and independently in literature discussion groups. Before beginning a novel study in this way, the teacher should provide the whole class with opportunity to learn and practice completing each of the roles and bring them to the discussion group.

These roles include: Summarizer, Word Whiz, Humourist, Map Maker, Discussion Director, Illustrator, Character Analyst, Literary Luminary.

Students need to be given choice and ownership of their reading. All students who are reluctant readers need to have successful reading experiences.

\subsection{Literary Letters}

Writing letters and notes (in print or electronically) provides students with authentic reasons to practice their writing skills. It is even better when the recipient writes back !

Young children can write to their favorite book character. Arrange with an upper grade to respond to the letters.

Write to authors. Search out the address on the Internet or write to the publisher. Many authors will write back, especially if the student's letter catches their attention.

Write to publishers commenting on the books read, including suggestions for revisions, new covers, and sequels.

\subsection{Illustrations}

Drawing in response to reading has been a time-honoured method of 
responding to literature. But illustration can be much more than simply sketching 'my favorite part", when it requires returning to the text for a close and careful reading for details. This develops the skill of visualization from verbal information.

Provide students with a portion of the text which provides a detailed description of a character, a setting or an event, and have them create an illustration to match the text.

Design a new cover for the book according to what you think it was really about, or to whom it should be marketed.

Extend experiences with a picture book and with visual art by studying the style and medium used by the illustrator.

\section{Involving The Home}

From the earliest of exposures, the home and the school have a wonderful opportunity to open the world of literature to children. Engaging parents in a child's literacy program by keeping them informed and getting them involved has the potential to greatly enhance the child's reading, writing and thinking skills for the future.

Becoming a reader has little to do with reading difficult books and everything to do with the amount of reading one does. So let your child choose books, even if they are below his reading level.

Encourage your parents to read with their children from the very early ages. Stories are appealing until the teen years (and even then but the boys wouldn't admit it.) Listening to things being read encourages your boys to read well. When they see a model they respect, they will follow the example. So that means you need to read in front of your kids too. Be the model for them. Be the change that you want to see in the world.

\section{Conclusion}

In 1990, Simon Papert said: "Better learning will not come from finding better ways for the teacher to instruct, but from giving the learner better opportunities to construct."

Our job as teacher-librarians and educators is to excite students about learning, give them the skills to become independent learners, and then see that they have the resources and guidance to discover a new world for themselves.

\section{Bibliography}

Australian School Library Association. “A Teacher Librarian Advocate's Guide to Building Information Literate School Communities" in ASLA Advocacy Kit 200629 p.

http://www.asla.org.au/advocacy.kit.pdf 
Beers, G. Kylene (1996) "No Time, No Interest, No Way": Three Voices of Aliteracy., in School Library Journal, Vol. 42, no. 2, p. 30-33

Bromley, Karen, Linda Irwin-De Vitis, and Marcia Modlo (1995) Graphic Organizers: Visual Strategies for Active Learning. Scholastic. 120 p.

Canada. Manitoba Education, Citizenship \& Youth. Instruction, Curriculum \& Assessment Branch and University of Manitoba Faculty of Education (2005) Literacy Across the Curriculum: Summer Institute 2005 in Winnipeg, Manitoba. Variously paged.

Canada. Manitoba Young Readers' Choice Award - Read and Vote for our Favorite Canadian Book. Sponsored by the Manitoba School Library Association. Vol. 34, No. 1 Autumn 2006, p. $13-18$

Canada. National Library and Archives. Read Up On It 2006-2007 - Aboriginal Stories. http://www.collectionscanada.ca

Canada. Ontario Education. Me Read? No Way! A Practical Guide to Improving Boys' Literacy Skills. $59 \mathrm{p} \quad \underline{\text { http://www.edu.gov.on.ca }}$

Canada. Ontario School Library Association. (2006) Ontario's Teacher Librarians' Toolkit. http://www.accessola.com/osla/toolkit/home.html

Canadian Library Association. Action For Literacy Interest Group. Libraries and Literacy: A Decade in Review - A Background Paper Prepared for the National Summit on Libraries and Literacy : Moving Forward, May 2006. Greg Kelner, Co-Convenor, AFLIG. http://www.nald.ca/summit/bkgrdpap.pdf

Clearing House on Reading, English and Communications, an information repository at the Indiana University School of Education. Dr. Carl B. Smith, Director. http://reading.indiana.edu/

Daly, Caroline (2002) Literature Search on Improving Boys' Writing. London: Office for Standards in Education (OFSTED) UK http://www.literacytrust.org.uk/Research/genderresearchindex.html

Daniels, Harvey (2002) Literature Circles: Voice and Choice in Book Clubs and Reading Groups. Stenhouse.

Daniels, Harvey (2003) Literature Circle: How Can You Grade3 Literature Circles ?" in Voices From the Middle, Vol. 11, no. 1 Education Module, pg. 52

Ellis, Susan S and Susan F. Whalen (1990) Cooperative Learning: Getting Started. Scholastic. $72 \mathrm{p}$. 
Hall, Susan (1994) Using Picture Storybooks to Teach Literary Devices. Oryx Press

International Association of School Librarianship. Special Interest Group - Literacy. Coordinator - Dr. Lesley Farmer. http://www.iasl-slo.org/sig infoliteracy.html

International Federation of Library Associations and Institutions. IFLANET. Reading Section. http://www.ifla.org

Kiwanis International Read-a-thon 2006-2007

http://www.kiwanisreadathon.org

Lenz, D. Keith (2006) "Creating School-Wide Conditions for High-Quality Learning Strategy Classroom Instruction", in Intervention in School and Clinic Vol. 41, No. 5, May ISSN: 10534512 p. $261-267$

Lyton, G. Reid (2000) "Why Some Children Have Difficulties Learning to Read" in Reading Rockets http://www.readingrockets.org/article/296

MacDonnell, Colleen (2004) "Making the case for pleasure reading", in Teacher Librarian: Journal of the School Library Professional, Vol. 31, No. 4, April

McNicol, Sarah (2007) Teenagers, Reading \& Censorship: Teenagers' views on censorship in libraries - A report looking at teenagers' attitudes towards censorship of their reading habits and library use based on a series of focus groups with 88 young people. University of Birmingham. http://www.ebase.uce.ac.uk/docs/censorship-teenage-focus-groups-report.pdf http://www.ebase.uce.ac.uk/projects/censorship resources.htm

Ogle, D. M. (1986) "K-W-L: A Teaching Model That Develops Active Reading of Expository Text", in Reading Teacher, vol. 39, p. 564-570

Pirie, Bruce (2002) Teenage Boys and High school English. Boynton/Cook

Reading A-Z .Com is an outstanding on-line resource on teaching materials, both fiction and non-fiction, for use with elementary and middle school students. He has a large collection of quality titles, supported with lesson guides, questions, and templates.

http://www.readinga-z.com

Reading through Canada.

http://www.umaine.edu/canam $/ \mathrm{k}-$

12outreach/Cankidlitppt/Canadian\%20literature\%powerpoint4.ppt

http://www.bookcentre.ca/awards/award ind/index.shtml

http://www.ucalgary.ca/ dkbrown/canawards.html

http://www.penguin.ca/static/cs/o/nf browseawards.html

http://psas.bctf.ca/BCTLA/bookawards.htm 
Roettger, Doris. (1989), Using Literature to Extend and Enrich the Basal Program using Paterson, Katherine. Bridge to Terabithia. Perfection Form Co. $49 \mathrm{p}$

Rog, Lori \& Barbara McNeil (1997) For the Love of Literature: Regina Public Schools Seminars. [Canada] Regina Board of Education. 94 p.

Rowley, Barbara. (2006) "The Joy of Reading: How to Keep It Fun and Fresh, for Babies, Big Kids and You", in Parenting Magazine http://www.parenting.com/parenting/child/article/0,19840,1226404,00.html

Schrock, Kathleen B. (2006) Kathy Schrock's Guide for Educators

http://discoveryschool.com/schrockguide/

Shepard, Aaron. Aaron Shepard's RT Page: Scripts and Tips for Reader's Theater http://www.aaronshep.com/rt/

Sullivan, Michael. (2003) Connecting Boys with Books: What Libraries Can Do. American Library Association. ISBN 0-8389-0849-7 $121 \mathrm{p}$

"Teen Reading: The challenge to create lifelong readers"(2000) in School Libraries in Canada: The Journal of the Canadian School Library Association. Vol. 19, no. 4 whole issue

Tomlinson, Carol Ann (1999) The Differentiated Classroom: Responding to the Needs of All Learners. Association for Supervision and Curriculum Development.

ISBN 0-87120-342-1 $131 \mathrm{p}$.

Tomlinson, Carol Ann \& Susan Demirsky Allan (2000) Leadership for Differentiating Schools and Classrooms. Association for Supervision and Curriculum Development. ISBN 0-87120-502-5 $166 \mathrm{p}$.

Knowledge is not enough; We must apply it. Willing is not enough; We must do it. - Goethe 


\section{BRIEF PERSONAL RESUME}

Gerald Brown retired as Chief Librarian from Winnipeg School Division, Manitoba, Canada in 1992. That system had 80 schools, 3500 teachers and 55000 students. He was responsible for all aspects of school librarian service, audio visual \& computer software and equipment repair services, and an ordering, acquisition and cataloging program for all materials ordered by the schools. The system was highly regarded for its program of school library and program implementation, and for its staff development programs.

Since that time he has been active as a consultant in 36 countries around the world in the area of school library \& information services. His special interests are information literacy, reading, and applying problem-solving models through the SLIS setting. He has been attending and lead presentations at the Crimea conferences in 2003, 2004, 2005. 